\title{
The Management of TMD, MPD With Internal Derangement- A Case Report
}

ISSN: 2637-7764

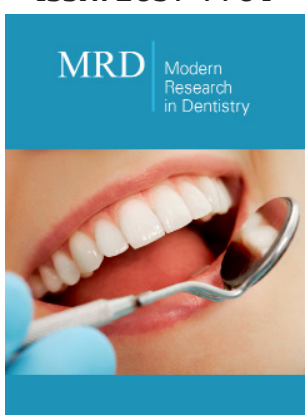

*Corresponding author: Alammar AM, Graduated from Tufts University, dental school for MS \& King saud university BDS, Dammam 31241, Saudi Arabia

Submission: 㘹 October 08, 2020

Published: 制October 30, 2020

Volume 5 - Issue 4

How to cite this article: Alammar AM. The Management of TMD, MPD With Internal Derangement- A Case Report. Mod Res Dent. 5(4). MRD. 000619. 2020. DOI: 10.31031/MRD.2020.05.000619

Copyright@ Alammar AM, This article is distributed under the terms of the Creative Commons Attribution 4.0 International License, which permits unrestricted use and redistribution provided that the original author and source are credited.

\section{Allammar $\mathrm{AM}^{*}$}

Graduated from Tufts University, dental school for MS \& King saud university BDS, Dammam 31241, Saudi Arabia

\begin{abstract}
The management of temporomandibular disorders (TMD) associated with the purpose of the present case report is to review the etiological factors and bilateral anterior disc displacement with reduction, abnormal masticatory and cervical muscles activity, Bruxism habit and malocclusion. Patient was successfully free of pain symptoms with jaw reposition occlusal splint, night Farrar splint, medication, physical therapy, trigger point injection and at the end for orthodontic treatment.
\end{abstract}

\section{Chief Complain}

A 35-year female patient presented to the Orofacial and Temporomandibular disorder (TMD) pain management clinic referred from general dentist. Her complain more pain left side than right of the jaw extended to preauricular area, earache some time with pressure, headache worse in the morning, joint sound more left side than right (clicking), grinding teeth while sleeping, poorly sleep, tired while eating, neck and shoulder muscle tight and painful $[1,2]$. The problem began 7 year ago and the symptoms increasing gradually, patient had orthodontic treatment at age of 14 .

\section{Medical History \\ Nothing abnormal detected.}

\section{Extra Oral and Intraoral Examination}

Restriction of mouth opening the patient opened $25 \mathrm{~mm}$ with a slight deviation to the right side. Clicking in in both temporomandibular joint (TMJ). The lateral and forward movement jaw restricted and painful $[3,4]$. The masticatory and cervical muscles very tender and painful to palpation. The dentation was class I right side and class II left side with notice of wear upper and lower teeth. Deep bite $3 \mathrm{~mm}$.

\section{Radiographic Examination}

Panoramic (OPG) showed slightly condyle degeneration both sides. Magnetic resonance imaging (MRI) showed anterior disc displacement with open and closed movement left and right TMJ.

\section{Diagnosis}

Myofascial pain and dysfunction (MPD). Temporomandibular disorder (TMD) with internal derangement with reduction right and left side of TMJ. Bruxism possible related to stress. Jaw shifted to left side.

\section{Treatment Plan}

Phase I: Occlusal splint for upper and lower jaw, Physical therapy, Medication and Trigger point injection.

Phase II: Orthodontic treatment after the patient free of symptoms to correct the occlusion and up righting post teeth to increase vertical dimension. 


\section{Treatment}

Lower reposition appliance (LOA) to keep the mandible anteriorly positioned (none click position) the patient well wore the appliance during the day only. Upper Farrar appliance with anterior vamp for the sleeping time. Trigger point injected at temporalis, masseteric and trapezius muscle right and left sides. Medication prescribed Chlorzoxazone 250mg \& Paracetamol $300 \mathrm{mg}$ two capsule three time a day for two weeks. Patient given physical therapy instruction and exercise to practice twice per day.

\section{Prognosis}

The patient symptoms improved gradually she is free of pain after eight weeks, she advised to continue the upper and lower appliances. The appliances was adjust every three weeks for six months, her TMJ still clicking but free of tender and pain $[5,6]$. Then patient referred to orthodontic treatment to start phase II treatment.

\section{Conclusion}

Temporomandibular disorder (TMD), Myofascial pain and dysfunction (MPD), internal derangement and bruxism remains a difficult condition to manage. However, while the bruxism was controlled the symptom of pain, fatigue, tender, earache been resolved and sleeping improved. Clicking still there without pain but it possible to disappear after correcting the deep bite and the occlusions by orthodontic treatment.

\section{References}

1. Franklin D, Bruce S, William M (1985) TMJ Internal Derangement \& Arthrosis, St. Louis, Missouri, United State of America 27: 138.

2. McNeill C (1993) Temporomandibular disorders guidelines for classification, assessment, and management. The American Academy of Orofacial Pain, Quintessence Publishing Co, Illinois, United State of America, pp. 42-55.

3. Eversole LR, Machado L (1985) Temporomandibular joint internal derangements and associated neuromuscular disorders. J Am Dent Assoc 110(1): 69-79.

4. Smith SD (1987) Diagnosis and treatment of temporomandibular joint disorders. Journal of Pain and Symptom Management 2(3): 155-161.

5. Stegenga B, de Bont LGM (1996) Management of temporomandibular joint degenerative diseases, Springer, USA.

6. Birkhäuser Basel (1996) Switzerland. 